\title{
Higher education staff and Brexit. Is the UK losing the youngest and brightest from other EU countries?
}

Giulio Marini, Centre for Global Higher Education (CGHE), Institute of Education, UCL, UK

g.marini@ucl.ac.uk

\section{Abstract}

Since the Brexit referendum in 2016, and the formal act of triggering article 50 by Theresa May's cabinet in 2017, the UK has entered a period of negotiations, the outcome of which, and also the terms of the post-exiting phase, are still uncertain. In this period of uncertainty, the mobility of people is one of the main issues at stake. The topic is important for the higher education sector where the percentage of (other) European Union staff in UK universities has grown at an impressive rate in recent years before the Brexit referendum. This paper draws from official Higher Education Statistic Agency (HESA) data to investigate if there is any inversion of this trend in the British system, arguing that some "Brexodus" of academic staff - meaning a decrease in the percentage of other EU nationals - has already started for some academics, namely the youngest and the brightest.

\section{Introduction. The relevance of the topic}

Globalization as a process of competition implies that acquiring talent is itself proof of success. This is true in the field of higher education too (Li \& Lowe 2015; Robertson 2010; Altbach 2004). Yet, contemporary western societies seem to reject higher numbers of immigrants. Acquiring talent is regarded as an emerging and urgent problem by much public opinion. The issue intertwines higher education and skilled workers because the connection between being an alumnus of a country and becoming a skilled 
worker in the same country is one of the most important "pull" dynamics (Furukawa et al. 2013; Kim et al. 2011).

The 'war for talent' (Michaels et al. 2001) is crucial yet faces possible rejection by indigenous public opinions. Post-global crisis discourse was already mitigating the term "war", highlighting the necessity to see talent not in an absolute void, but in its context (Beechler \& Woodward 2009). This paradox also questions what Richard Florida (2005) proposed about the creative classes and their environment: although they might live in cities enshrined with cosmopolitan and liberal values, other components of society might see this type of presence as not desirable. Peter Scott (2015) already put this into the frame of higher education as an inevitable byproduct of globalization. Empirical evidence confirms this backlash in processes of globalization (Colantone \& Stanig 2018). Nevertheless, the quest for fewer immigrants is probably detrimental in any sector, if the highest goal is that of economic development.

This paper looks at the issue of international talent, particularly in the higher education sector, arguing that Brexit might have generated less favorable conditions for other EU nationals to live in the UK. According to relevant players in the field - University UK (UUK) the association of the employers of British universities - other EU nationals are good contributors to the British economy. It is also not under dispute that international employees, either from other European Union countries or beyond, are net contributors to the success of British higher education (UUK 2018). As empirical evidence shows (Lin et al. 2008), having a continuous flow of immigrants, including in academia, is essential to being a leading country in the higher education sector. A counterproof of this is the attention that countries aspiring to global prestige spend on talent and the respective brain gain - China being a case in point (Welch \& Zhen 2008). To have scholars from more places is pivotal to success, especially if they are the youngest and the brightest.

In relation to this issue of attractiveness, the British HE sector showed confidence also at the wake of the referendum, as the University \& Colleges Employers Association (UCEA - the most comprehensive association of employers in the sector) affirms (UCEA 2017). Nevertheless, problems in recruiting to replace the people who are already leaving has already been condemned, the case of the Chartered Association of the Business Schools (CABS) in the UK being a case in point (CABS 2017). UUK is also attentive to the issue of retention (UKK 2018).

"Brexodus" emerged at the wake of the Brexit referendum as a possible scenario of impoverishment. It is an attractive term to highlight what an actual Brexit may look like. Drawing from Biblical Exodus, Brexodus would refer to a massive change of residency for a large portion of "other European Union" (othEU) citizens currently living in the UK. In this paper, Brexodus is understood as any possible change of othEU employees in the time period studied. In this sense, Brexodus would be also a small reduction of 
othEU instead of a large exodus. Brexodus could be also a smaller rate of increase in comparison to previous years, although in this case any argument ought to be tempered. The reason for this wide definition of Brexodus is that the paper aims at tracing any interference caused by Brexit since the negotiations are still open and any insights can have an appreciable impact.

Brexodus as a possible consequence of Brexit also opens up a brand new perspective: the impoverishment of a country with a large "brain gain" - including impoverishment from the possibility of less brain gain, and not necessarily a passage into a "brain drain" condition. Strikingly enough, the current perspective moved from how to improve the attractiveness (Ackers \& Gill 2005) of the UK into questions about retention of the "good immigrants". The Brexodus perspective is also reverting the assumptions of the most recent debate about the "battle for talent" (Brücker et al. 2012). Instead of a more crowded competition among nations, Brexit presents a possible retreat of one of the most successful countries in the global higher education competition. Yet, Brexodus might be a reshuffle of nationalities, in the sense that EU nationals could be replaced by other nationals - either from more developed countries (i.e. the US) or others that could belong - or not - to the Commonwealth.

In terms of "talent", Brexit might also trigger a worse than zero-sum game at European level - meaning the UK losing something but other non European countries replacing the UK in attracting othEU academics. Many European countries, especially Central and Eastern ones (Leisyte \& Rose 2017) are not capable of attracting scholars. Arguably, some others from Southern Europe are also unable. On the contrary, many othEU nationals rely on the UK - as the main "almost domestic" destination - as a good possible career option. Brexit may also end a European win-win game, establishing a possible lose-lose one instead, if the features of contemporary Europe in terms of talent requirements, or talent deficit, are taken into account (van der Wende 2015). Nevertheless, in globalized higher education, many places may welcome academics, as the cases of Kazakhstan (Lee \& Kuzhabekova 2017) or Singapore (Ng 2013) show.

Some public debate also arose about intentions by othEU to leave the UK. In the HE sector (and research institutions), a recent study found that $25 \%$ of respondents with othEU nationality would leave the UK because of Brexit (Guthrie et al. 2017).

Intentions are important; concrete actions are more important and likely to be different, namely lower in numbers. To leave a country may take time to become an action. Declarations to seriously consider leaving the UK because of Brexit might be just a way to impress public opinion, policy makers, or just a personal outburst of disappointment.

For all these reasons, one of the most important implications of Brexit is the actual behavior of othEU nationals. Are they continuing to grow as in recent years? Are they constant, or are they already diminishing? A shortage of skilled personnel from other EU countries has already occurred quite distinctively, if all sectors are analysed (Shapira 2018). The higher education sector needs a specific analysis. 
Ultimately, "Brexodus" in higher education as widely defined here would be one of the clearest indicators that the British system is undermining its current "first tier" place in global prestige in HE (Marginson 2006). Although any result might be small in difference from the recent past, it is strategic to trace changes from this point in time without waiting for larger figures to become manifest.

\section{Data}

The Higher Education Statistics Agency (HESA) provides information about staff in British higher education. It represents the only reliable source of information for the whole country. Data refer to employees or other staff whose employer is British, not considering the issue of possible different forms of shorter mobility of academics (Teichler 2015; Maadad \& Tight 2014). According to tight privacy settings, which also apply to the most fine-grained degree of access to data (called "Golden HEIDI+" in distinction to "Silver HEIDI+" or other public releases), there are substantial limits to pursuing typical scientific data treatment. Data are stocks; fluxes, or disentangled amounts of people exiting and entering the system (for which respective stocks compose the addends of subtraction) are not available. In particular, microdata, although anonymous, are not available. Data can only be browsed online, and downloaded as "rounded to 5 units". For this reason, the higher the number of variables, and the less statistically robust the cells in one's launch, the less accurate the information that will result. Moreover, for the variable nationality of staff, a large percentage of staff was not labelled in the first years of the available time series. In the 2004/5 academic year, the percentage of "unknown nationality" was $7.4 \%$. In last available year (2016/17) it was $0.8 \%$. This progressive reduction is probably due to some absorption achieved along years. In order to analyse some time series looking at other EU nationals, it is essential to consider how to treat the progressively shrinking missing values. Considering that these missing values are much more likely to refer to foreigners, we redistributed the unknown nationalities between OthEU and the other aggregation of foreigners, the nonEuropean Union citizens ( $\mathrm{nEU}$ ) according to the percentages they respectively had in a specific year. Data shown in this paper are about full time equivalent numbers. For all the figures shown, any different treatment of missing values does not change the findings discussed in a relevant way. Figures refer to full time equivalent for all personnel in higher education, with the exclusion of non-academic atypical.

Given these caveats, time series about OthEU nationals by several variables are provided in order to understand if, and by which subgroups, Brexodus is happening. For all figures, the percentages represent the quota of OthEU over the total of the sector, either British people or other foreigners. A reduction in percentage does not necessarily 
equal a fall in absolute numbers, as the system is still growing in absolute terms in recent years, and definitely also for the 2016/17 academic year.

\section{Findings}

Until the Brexit referendum and the beginning of Brexit negotiations, the time series shows a very simple trend: othEU nationals were increasing steadily among UK higher education staff. The academic year $2016 / 17$ is the first one that falls entirely within the Brexit negotiations. It is the first year that might contemplate any "Brexodus" as defined in the introduction. Any consideration should look primarily at the difference between the 2015/16 and 2016/17 academic years, taking into account the trend shown in the previous 12 years also.

\section{Grand total and Russell Group universities}

The grand total of the academic workforce indicates that before the referendum the growth of othEU nationals in the system was remarkable, especially in the years between 2011 and 2015 (Figure 1). In the first year of Brexit negotiations, the overall percentage is still increasing, but is almost flat. Figure 1 also provides the same statistics for the universities that belong to the Russell Group, the most research-intensive UK universities. In these universities, the percentage of othEU nationals is much higher and the growth in the last year (2016/2017) is still present, though much reduced in comparison with the previous three years.

Figure 1. Percentages of Other EU nationals over the total of staff in UK higher education institutions. Grand total and Russell Group universities. Time series

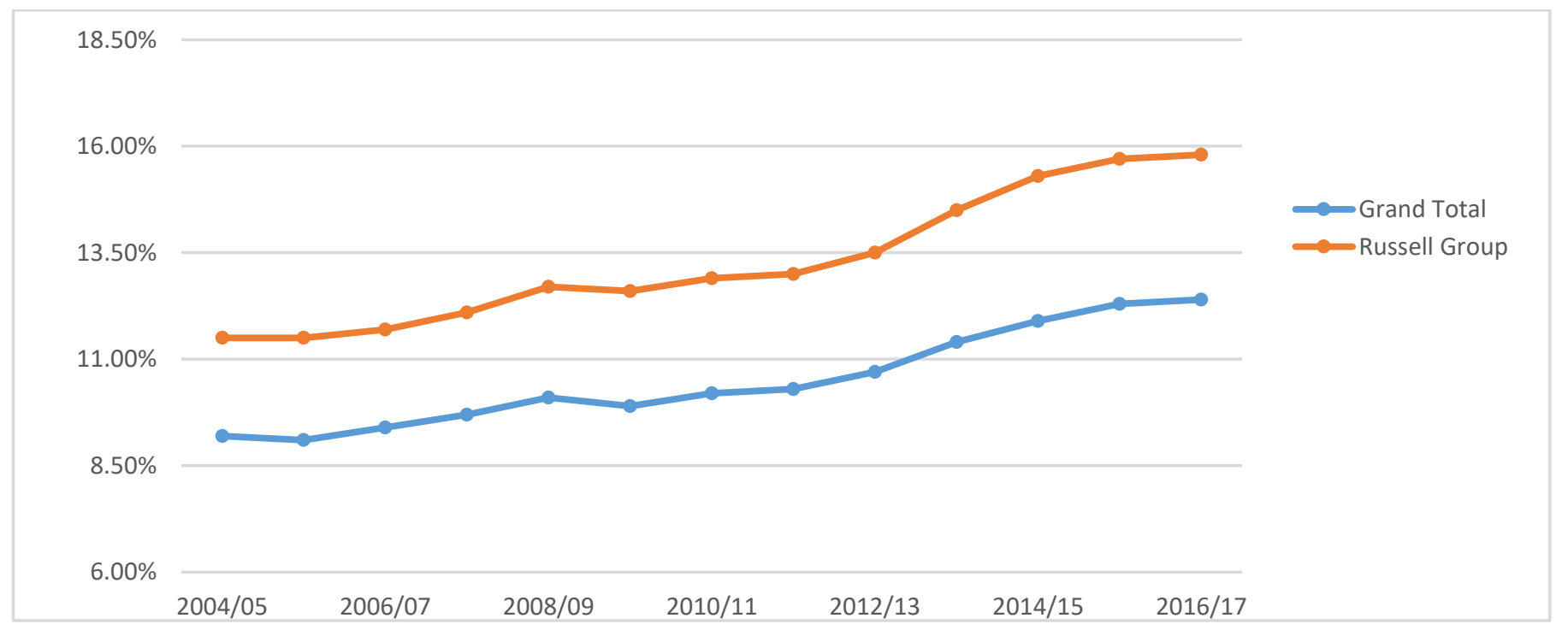

Source: HESA data, HEIDI+ Golden access. 
This figure also suggests that, at least for the majority of scholars, the UK is still an attractive place. Usually established academics - according to literature from a European Commission project (MORE2 2013) - are more likely to be poached back in other EU countries. They are also on average more likely to see mobility as feasible behavior. The category of the "stars" nevertheless represents a minority. A study led in Scotland suggests that if leading scholars start to leave their jobs for another one, or no longer regard a place as attractive, sooner or later the main proportion of academics who are not "stars" will also start to find that place overall less attractive (Kreber \& Hounsell 2014).

\section{Age}

To analyse by age is one of the few ways to look at the possible future trends, assuming that a person already in a career track in a country is less likely to change residence in comparison to someone who is starting his/hers. As Figure 2 shows, othEU nationals have increased notably, including in the most recent year, if aged 35-49. Interestingly, the percentage of staff aged 34 or less in the last academic year went down, representing a possible reduction of othEU nationals in perspective. It is worth keeping in mind that mobility for academics, as well as for researchers outside academia, is a combination of barriers, career development opportunities, and personal constraints (Guthrie et al. 2017). All these factors are more likely to be less pressing for those aged 34 or less (i.e. family issues). Brexit may influence those at the beginning of their careers more, both in terms of their long-term perspectives and the fewer constraints they face in their personal lives. This figure is apparently in contradiction with Børing et al. (2015) in regarding older people as more likely to be migrants. Nevertheless, literature of mobility of academics gives more coherence to this finding (Ackers 2008; Ackers \& Gill 2008).

Figure 2. Percentages of Other EU nationals over the total of staff in UK higher education institutions; age. Time series 


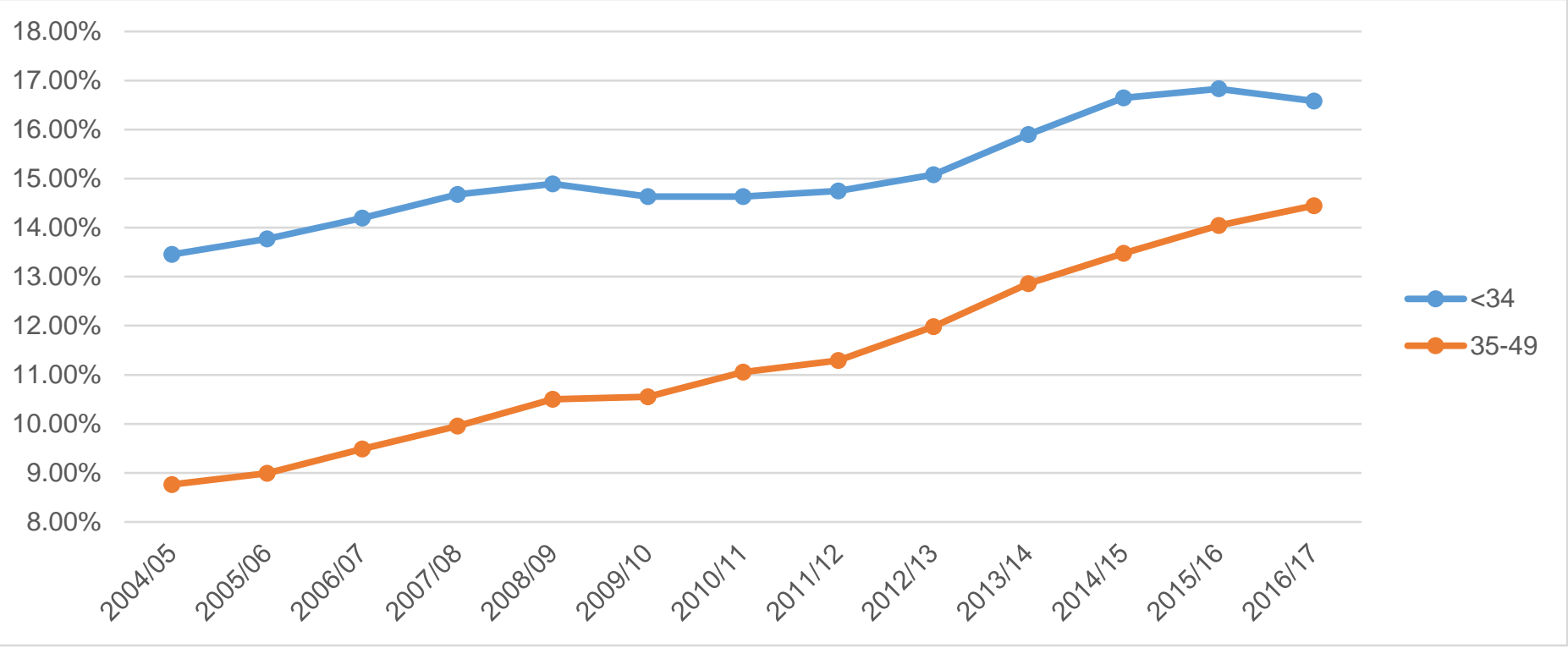

Source: HESA data, HEIDI+ Golden access.

\section{Academic function}

Academic function distinguishes between what academics are expected to do by contract on a regular basis. This variable excludes not-academic people, such as "professionals" in HESA jargon. Teaching and Research (T\&R) contracts are the typical and traditional contracts that require academics to perform both teaching and research. These are usually the most secure contract as they are more likely to be permanent. For this contract, the career track is also clearer. The teaching only and the research only tracks have less clear career paths due to the fact that they are both more recent. In general, teaching only contracts $(\mathrm{T})$ are also those that are more likely to be precarious, casualised, or hourly paid. A fair rank of preference in terms of length and contractual conditions would be: T\&R; R (research only); T (teaching only). Figure 3 shows that othEU nationals are very highly represented in research only contracts, but also that they stopped growing in the last available academic year. Other EU nationals were the least frequent 15 years ago in T\&R contracts, but their increase has been stable, including in the last year. This might mean that the system is including progressively othEU nationals regardless of Brexit, and also that othEU are applying for this type of employment. On the contrary, research only personnel decreased in the last year. A possible overall explanation for this trend is that othEU nationals are selecting more than previously the supposedly best type of contract to stay in the UK (the traditional teaching and research one), if they can. They might have begun to opt out whenever a teaching 
only contract was to be renewed, or they might have started to be relatively less eager to even apply for these positions.

Figure 3. Percentages of Other EU nationals over the total of staff in UK higher education institutions; academic functions ( $T=$ teaching only; $R=$ research only; $T \& R=$ traditional teaching and research contract). Time series

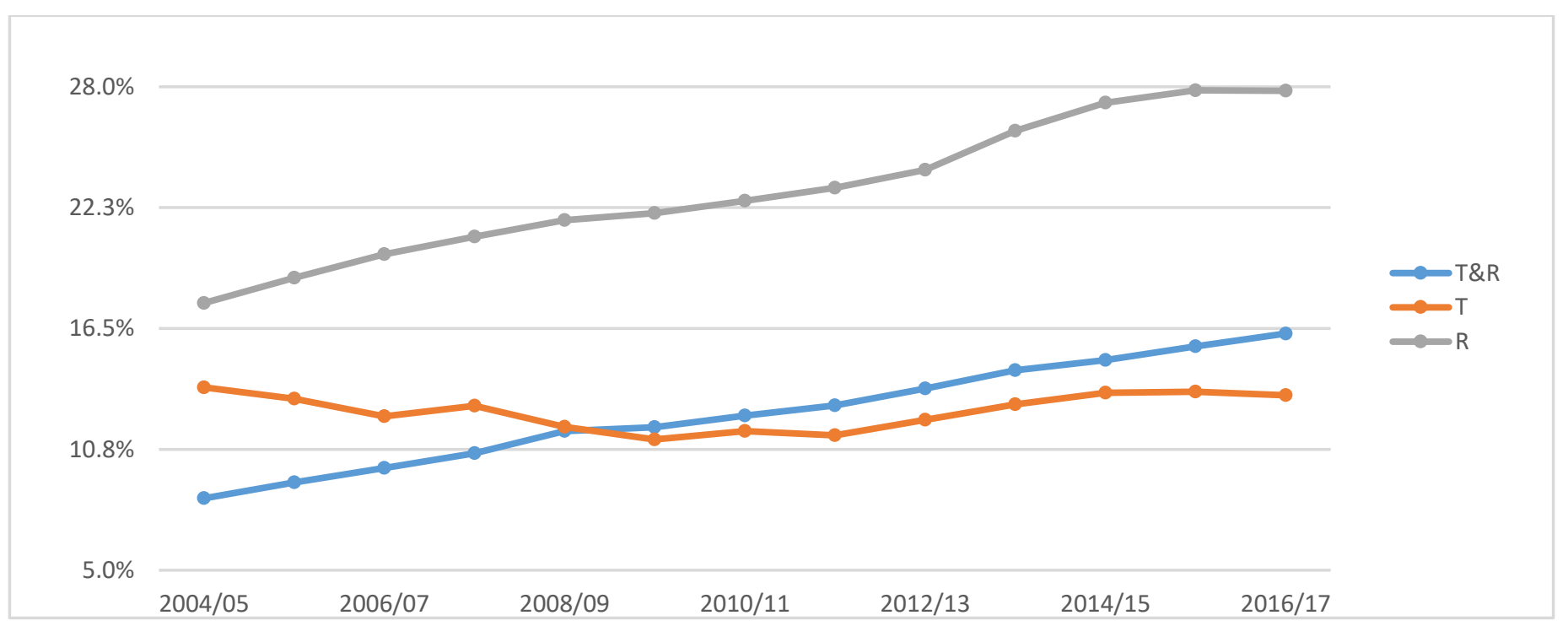

Source: HESA data, HEIDI+ Golden access.

\section{Type of contract}

The type of contract represents the formal length of the contract. "Open-ended" means substantially permanent. Fixed term is a contract that might be renewed and might bring a permanent position, but in the current context is likely to be linked to externally funded sources or to specific projects for which the employee is not fully independent. More recently, they might replace the probation period in a typical fixed-term one, assuming the contract will be turned into a permanent or open-ended one if the employer is satisfied. Atypical contracts include more casualiased positions and they are also more likely to not be full time.

Similar to the previous figure, only open-ended contracts are continuing to grow, starting from a much lower percentage of the total of academic staff. Atypicals fluctuated and appear to be substantially stable, whereas the fixed term positions, still by far overrepresented by othEU nationals, have seen an inversion of trend during the last observed year. 
Figure 4. Percentages of Other EU nationals over the total of staff in UK higher education institutions; type of contract. Time series

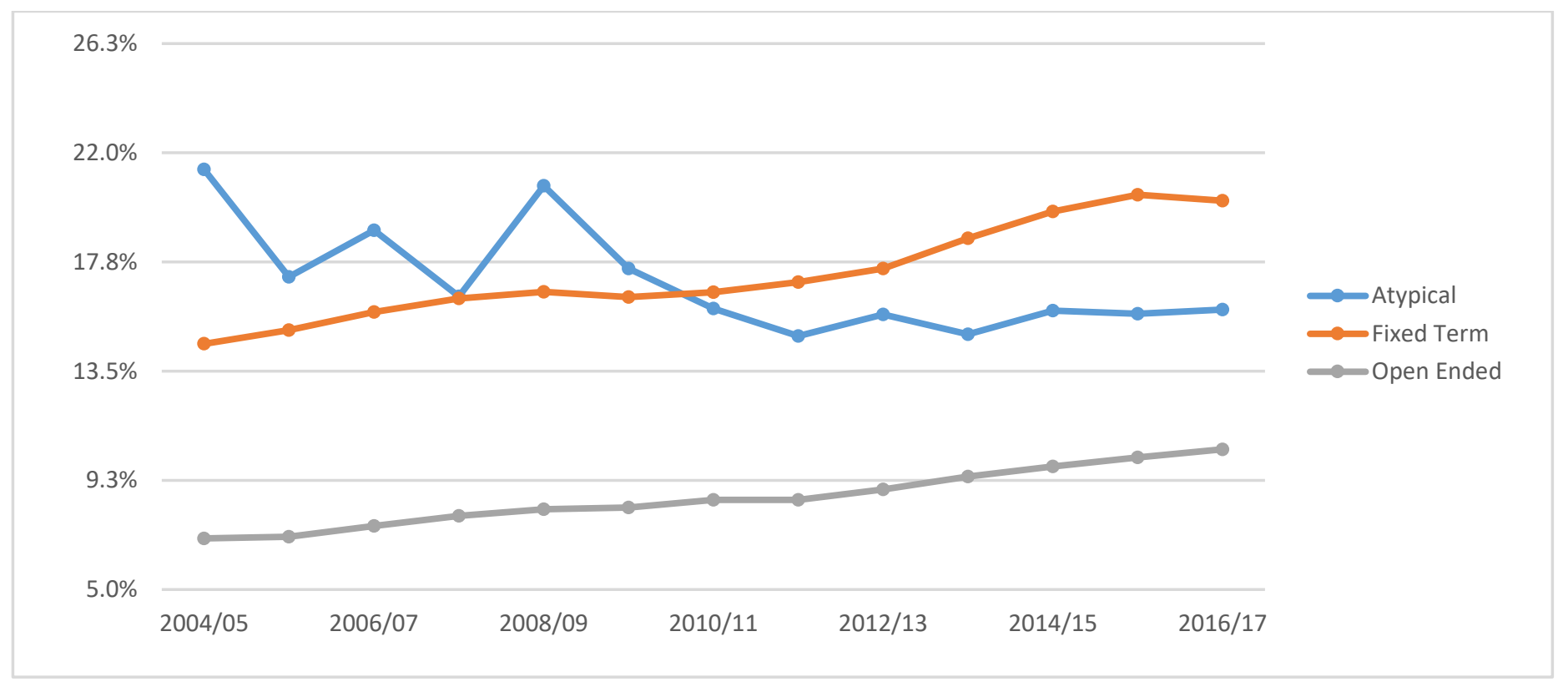

Source: HESA data, HEIDI+ Golden access.

Source of funding

One of the alternative ways to look at the status and degree of security of one's position in the contemporary UK HE system is by the source of one's salary. HESA delivers some categories: "wholly funded by HE", which represents the most secure source of funding; "partially funded by the HE sector" (here omitted); "other sources"; "not applicable" (omitted in Fig. 5) and "multiple sources" (omitted in Fig. 5). Figure 5 aims to distinguish those who are in the most secure source (wholly funded by HE) from those who are not ("other sources"). It appears that othEU nationals are much more frequently on "other sources", but, in the last academic year, this percentage remained flat, if not decreased, although in the previous years the rate of growth was remarkable. On the contrary, othEU nationals wholly funded by HE are continuing to grow. It is possible that "other sources" represents to some extent an easier ability to leave the country when a contract expires, whereas for the other case, the wholly funded by HE, an academic may consider it attractive to leave the country only if "poached" or compelled by other reasons. 
Figure 5. Percentages of Other EU nationals over the total of staff in UK higher education institutions; source of employee salary. Time series

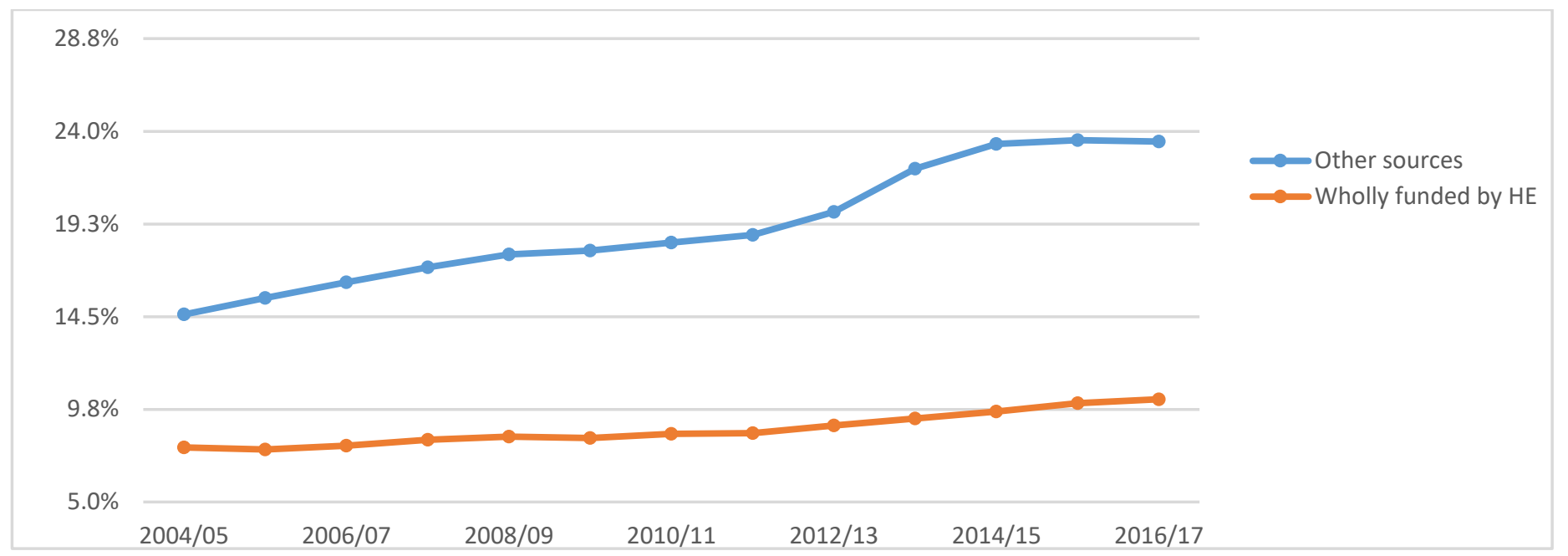

Source: HESA data, HEIDI+ Golden access.

Salary bands

HESA also provides statistics about some six groups of salary bands. As per Figure 6, Salary 1 (S1) is the lowest and S6 the highest. Figure 6 shows that othEU nationals are proportionally increasing in lower bands (S1, less clearly $\mathrm{S} 2$ ). Intermediate salary spines (S3) are decreasing in percentage. S4, the most frequent, is flat in the last academic year. Regarding the higher bands, there is an increase of othEU staff over the total personnel in UK higher education providers. This might be seen as an effect of career progression of some cohorts of othEU in the British HE system who performed according to national and institutional standards. For the lowest bands, the first year of Brexit indicates that the UK is still increasing the percentage of othEU nationals. It is also possible that especially for S1 and S2 bands, the population in question is composed by temporary staff, part-timers, or other types of personnel.

Figure 6. Percentages of Other EU nationals over the total of staff in UK higher education institutions; salary bands. Time series 


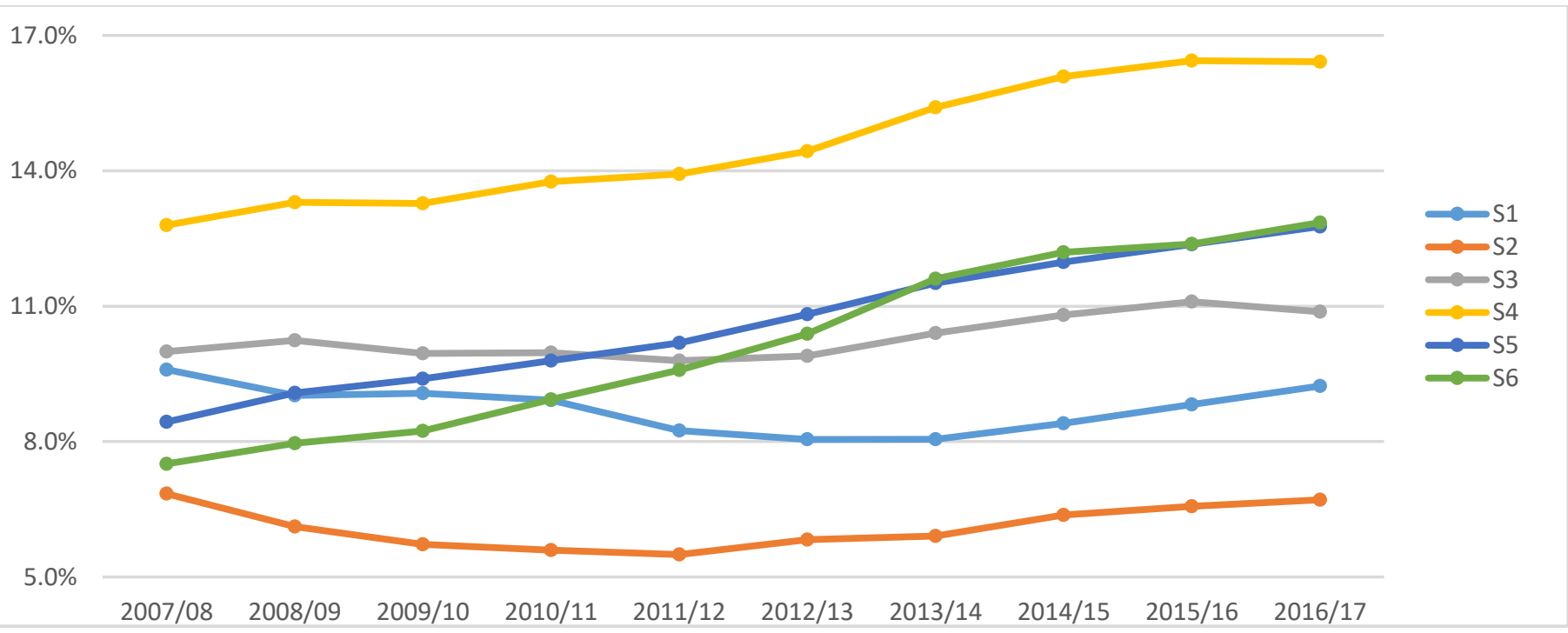

Source: HESA data, HEIDI+ Golden access.

Salary bands for younger employed

Considering the most interesting figures shown in the second subsection about age (Figure 2) and the last one (Figure 6), which is a fair proxy of one's degree of talent if kept at parity of age, it is interesting to cross age by salary bands. In this regard, Figure 7 aims at disentangling which younger staff (34 years old or less) in British universities are increasing or decreasing in the last year in terms of salary bands. As the chart shows, higher salary bands (S5, S4 and S3) had a small reduction in the last year, whereas othEU staff in S1 and S2 had some increases. With the exception of S6, excluded for not being statistically frequent in absolute numbers, this figure shows that the UK in the last year attracted those othEU nationals who deserve a higher salary a little less, and attracted those who earn a lower salary slightly more. This figure might prove that the country has lost some of its grip in attracting the most talented personnel for the sector - namely the brightest within the youngest.

Figure 7. Percentages of Other EU nationals over the total of staff in UK higher education institutions aged 34 or less by salary bands. Time series 


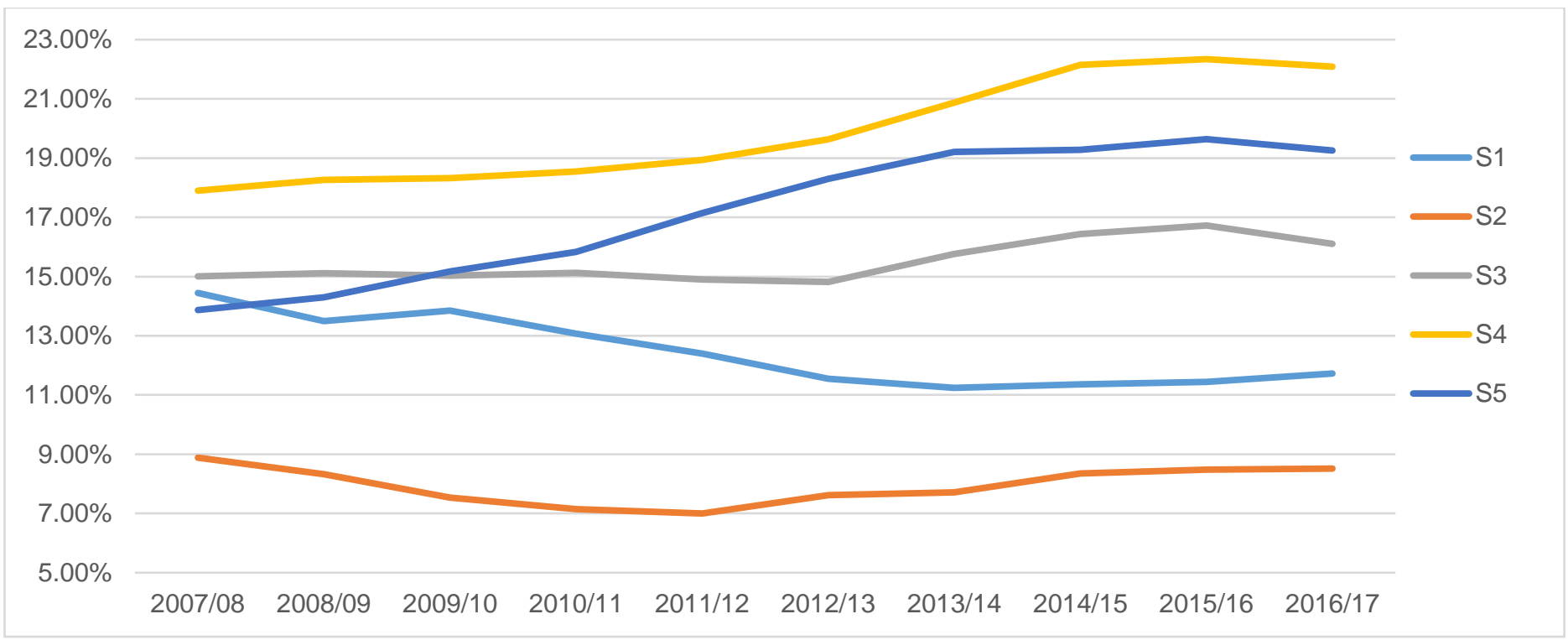

Source: HESA data, HEIDI+ Golden access.

Source: HESA data, HEIDI+ Golden access.

\section{Other variables}

Respective analyses by gender, disability, race, academic marker (academic and professionals) and standard occupation classification do not offer appreciable differences by nationality. Some further crossing of two or more variables from those above discussed do not yield further contribution.

\section{Discussion}

Although staff in HE might be keener than employees in other sectors to be mobile and many of the othEU nationals might have seriously considered and might still consider leaving the UK, in large part this is not happening, or at least this might have been largely compensated by new entrants in the net stock values. However, Brexit is impacting staff in $\mathrm{HE}$ according to these data. The trend is not reversed, for the moment, but the rate of growth of othEU in UK HE is reduced. Overall, from this statistical analysis, we can conclude that Brexodus is happening only among some groups, and only if a wide definition is considered. 
These figures let us understand that there is a general slowdown in othEU seeing the UK as a destination country. The figures about share of staff by age, in particular those aged 34 or less, are consistent with this argument. Especially for those in higher salary bands, arguably the most promising scholars, data reveal that there is a marginal reduction of othEU nationals in the UK. These figures should alarm the British HE system into not underestimating the consequences that Brexit is having today and its future prospects. It should also be noted, moreover, that the possibility of continuing to take part in European schemes such as the European Research Council (ERC) is probably key for this precious group of academics. Hosted projects branded ERC by country show that the UK is by far the first destination country for these European flagship projects with 1770 projects (Germany is second with $1252^{1}$ ). In other words, Brexit has a negative influence on the number of othEU nationals by simply making it harder to attract the best of them on the grounds that the UK risks being excluded in the future by some schemes and funding agencies. This dynamic would not be an "exodus"; it would entail a stalemate for the UK in embodying the role of the most successful country in the European pull component of talented juniors' mobility. Unfortunately, HESA data is not suitable for analysing fluxes. Other research strategies ought to look at this particular factor in the future.

Although some general figures point to the fact that in absolute terms there are more people entering UK higher education than exiting during the Brexit negotiation period (Hope 2018), these figures have shown that proportionally there are less younger scholars entering the system, and that the composition of othEU nationals has changed in the last year towards lower performing othEU nationals. This phenomenon is not desirable for the system, nor specifically demanded by public opinion that is more likely to support less competition in the supply side of the labour market for less skilled jobs, rather than seeing academic stars as a threat.

Overall, most academics from other European Union countries are simply continuing to develop their own careers if they have been in the UK already at the time Brexit negotiations commenced.

\section{Conclusions and policy implications}

Although the academic labour market is intrinsically separated from the generic migration processes linked to job mobility (Bauder 2012), problems caused by Brexit are on the horizon. Classical studies in migration policies (Piore 1979) demonstrated that lower skills migration and higher skills migration go hand to hand. Hardly any plan to "cherry-pick" the migrants may work without difficulties in its implementation. Yet, the

\footnotetext{
${ }^{1}$ https://erc.europa.eu/projects-figures/erc-funded-projects Data accessed on May 16 2018.
} 
idea to be "better off outside the European Union" sounds incautious, as all the efforts the UK is putting in place for the higher education sector have been just to keep things as they are today, or to minimize the risks of change from the status quo (House of Commons 2017a; 2017b). Moreover, a system of more complex visas and regulations, as for the moment Brexit seems to imply, would be detrimental for new entrants (Bauder 2006; Appelt et al. 2015). Points Based Scores (PBS) systems might continue to work in a post-Brexit phase, as they have previously worked for the UK (Boeri et al. 2012), but the terms once outside the European Union might differ in a substantial way.

Despite Theresa May declaring in her Florentine speech on September $22^{\text {nd }} 2017$ "we want you to stay" (May 2017), uncertainty is still ruling. Words, though important and genuine they might be, are not enough to prevent a loss of competitiveness in attracting academics, and these figures are prove that something has already happened regarding the most strategic of target immigrants.

Another topic will also be the quality of the experience of being a brand new immigrant out of the status of other European Union nationals within the European Union. Qualitative studies dedicated to academics (Scott Metcalfe 2016; Kim 2009; Kim 2014) demonstrate how relevant the European institutions are in smoothing the inevitable frictions of being immigrants in academia. At the same time, the European Union favors the nurturing factor of mobility in many ways. If, and the extent to which, these conditions will be lost will drive future research in the topic.

Brexit as such has still to happen. Nobody, at the moment, knows what specific regulations will be in place in 2019 , or commencing 2021 or any other date, in case a further transition period will be agreed by the parties negotiating Brexit. The terms of these conditions - including visa regulations and respective thresholds - will certainly have some weight in people's decisions whether to start a career in the UK, or to continue to have one in the UK, as empirical evidence suggests (Appelt et al. 2015). In addition, the terms of the partnerships between the European Union and the UK in European research schemes will affect dramatically in the mid and long term the capability of the UK to attract academics from the other European countries. Also, the attractiveness of the system as a whole for students might have a role: if the system will close itself to foreign students on the grounds that they are immigrants who are likely to remain in the UK (given the public opinion is not in favor of this phenomenon), there might also be fewer positions in absolute terms. Consequently, there will be less space for anyone.

The capacity of the British system to continue to be a leader worldwide, and definitely within Europe, is under question, but is not necessarily lost. For instance, any final decision about visas for researchers will influence European researchers' behavior towards a topic they did not detect before Brexit: "obtaining a visa or work permit" is by far the least of the problems researchers declare in pursuing mobility within Europe (MORE2 2013). For non European Union nationals the visa issue is the second of the 
barriers. It is mentioned almost three times more in comparison to EU nationals $(11.7 \%$ for EU nationals versus $29.6 \%$ by not EU nationals; MORE2 2013).

\section{In other words, global competition for talent may not be lost. As Universities UK affirmed recently (2018), the competition has just started.}

\section{References}

Ackers, L. \& Gill, B. (2005). Attracting and Retaining 'Early Career' Researchers in English Higher Education Institutions. Innovation, 18(3), 277-299

Ackers, L. \& Gill, B. (2008) Moving People and Knowledge: Scientific Mobility in an Enlarging European Union. Cheltenham, UK: Edward Elgar.

Ackers, L. (2008) Internationalisation, mobility and metrics: A new form of indirect discrimination? Minerva, 46, 411-35.

Altbach, P. G. (2004). Globalisation and the university: Myths and realities in an unequal world. Tertiary Education \& Management, 10(1), 3-25.

Appelt, S., van Beuzekom, B., Galindo-Rueda, F. \& de Pinho R. (2015). Which factors influence the international mobility of research scientists? in Geuna, A. (ed.) Global Mobility of Research Scientists: The Economics of Who Goes Where and Why. Amsterdam: Elsevier.

Bauder, H. (2006). Labor Movement: How Migration Regulates Labor Markets. Oxford University Press, New York.

Bauder, H. (2012). The International Mobility of Academics: A Labour Market Perspective. International Migration 53 (1): 83-96.

Beechler S., Woodward, I.C. (2009). The global "war for talent”. Journal of International Management 15, 273-285

Boeri, T., Brucker, H., Docquier, F., \& Rapoport, H. eds. (2012). Brain Drain and Brain Gain: The Global Competition to Attract High-Skilled Migrants. OUP Oxford.

Børing, P., Flanagan, K., Gagliardi, D., Kaloudis, A., \& Karakasidou, A. (2015). International mobility: Findings from a survey of researchers in the EU. Science and Public Policy, 42, 811-826.

Brücker, H., Bertoli, S., Facchini, G., Mayda, A.M., Peri, G. (2012). "Conclusions to Part I". In Boeri T., Brucker, H., Docquier, F., \& Rapoport, H. eds. (2012). Brain Drain and Brain Gain: The Global Competition to Attract High-Skilled Migrants. OUP Oxford.

CABS (2017). Annual Membership Survey 2017: Results. London.

Colantone, I., Stanig, P. (2018). Global Competition and Brexit. American Political Science Review. 112(2), 201-218

Florida, R. (2005). The Flight of the Creative Class: The New Global Competition for Talent, HarperBusiness.

Furukawa, T., Shirakawa, N., Okuwada, K. (2013). An empirical study of graduate student mobility underpinning research universities. Higher Education, 66:17-37

Guthrie, S., Lichten, C., Harte, E., Parks S., and Wooding S. (2017) International mobility of researchers. A survey of researchers in the UK, Santa Monica, California US:

https://www.rand.org/pubs/research_reports/RR1991.html 
Hope, C. (2018, May 10). Fears of 'Brexodus' of academics from Britain's universities are 'a myth', figures show. The Telegraph. Retrieved from: www.telegraph.co.uk

House of Commons, Education Committee (2017, April). Exiting the EU: challenges and opportunities for higher education: ninth report of session 2016-17. London, UK.

House of Commons, Education Committee (2017, October). Response to House of Commons, Education Committee Exiting the EU: challenges and opportunities for higher education: ninth report of session 2016-17. London, UK.

Kim, D., Bankart, C. \& Isdell, L. (2011). International doctorates: trends analysis on their decision to stay in US. Higher Education, 62(2), 141-161.

Kim, T. (2009). Shifting patterns of transnational academic mobility: A comparative and historical approach. Comparative Education, 45(3), 387-403

Kim, T. (2014). Internationalisation of higher education and global mobility. Comparative Education, 50:4, 507-509.

Kreber C., \& Hounsell, J., (2014). "Being an international academic: A phenomenological study of academic migrants adjusting to working and living in Scotland" In Academic Mobility. Emerald. 11, 9-33.

Lee, J.T., \& Kuzhabekova, A. (2017). Reverse flow in academic mobility from core to periphery: motivations of international faculty working in Kazakhstan. Higher Education, https://doi.org/10.1007/s10734-017-0213-2

Leisyte, L., \& Rose, A.L. (2017). Academic Staff Mobility in the Age of Trump and Brexit? International Higher Education, 89, p.5.

Li, Z. \& Lowe. J. (2015). Mobile student to mobile worker: the role of universities in the 'war for talent'. British Journal of Sociology of Education, 37:1, 11-29

Lin, Z., Pearce, R. \& Wang, W. (2009). Imported Talents: Demographic Characteristics, Achievement and Job Satisfaction of Foreign Born Full Time Faculty in Four-Year American Colleges. Higher Education, 57(6), 703-721

Maadad, N., Tight, M. (Eds.) (2014). "Editorial introduction" In Academic mobility. Emerald. 11, 1-7.

Marginson, S. (2006). Dynamics of national and global competition in higher education, Higher education, 52, $1-39$.

May, T. (2017, September 22). PM's Florence speech: a new era of cooperation and partnership between the UK and the EU. Retrieved from: https://www.gov.uk/government/speeches/pms-florence-speech-a-new-era-ofcooperation-and-partnership-between-the-uk-and-the-eu

Michaels, E., H. Handfield-Jones, and B. Axelrod. 2001. The War for Talent. Boston: Harvard Business Press. MORE2 (2013). Support for continued data collection and analysis concerning mobility patterns and career paths of researchers. EU Commission Report. Brussels: European Commission.

Ng, P.T. (2013). The global war for talent: responses and challenges in the Singapore higher education system. Journal of Higher Education Policy and Management, 35(3), 280-292.

Piore, M.J. (1979). Birds of Passage: Migrant Labor and Industrial Societies, Cambridge University Press, Cambridge.

Robertson, S. 2010. "Corporatisation, Competitiveness, Commercialization: New Logics in the Globalizing of UK Higher Education.” Globalisation, Societies and Education 8 (2): 191-203.

Scott Metcalfe, A. (2016) Nomadic political ontology and transnational academic mobility, Critical Studies in Education, 58:2, 131-149. 
Scott, P. (2015). Dynamics of Academic Mobility: Hegemonic Internationalisation or Fluid Globalisation. European Review, 23(1), 55-69.

Shapira M. (2018) Brexodus of EU citizens from the UK is picking up speed. The Conversation. $22^{\text {nd }}$ February 2018

Teichler, U. (2015). Academic Mobility and Migration: What We Know and What We Do Not Know. European Review, 23(1), 6-37.

UCEA (2017) Higher Education Workforce Survey 2017. London.

University UK (2018, March). How can the Government ensure Universities are best placed to Maximise their contribution to a successful and global UK post-EU exit? London. Retrieved from:

http://www.universitiesuk.ac.uk/policy-and-analysis/reports/Documents/2018/brexit-briefing-march-18.pdf

Van der Wende, M. (2015). International Academic Mobility: Towards a Concentration of the Minds in Europe. Research \& Occasional. Paper Series: CSHE.3.14, Center for Studies in Higher Education, University of Berkeley, US.

Welch, A.R., \& Zhen Z. (2008). Higher education and global talent flows: Brain drain, overseas Chinese intellectuals, and diasporic knowledge networks. Higher Education Policy, 21(4), 519-537. 